\section{S74 LUNG VOLUME REDUCTION: A LARGE-VOLUME SINGLE- CENTRE EXPERIENCE WITH AN ANALYSIS OF SEASONAL VARIATION}

ADG Rogers, AJB Kirk, R Bilancia. Golden Jubilee National Hospital, Glasgow, UK

\subsection{6/thorax-2021-BTSabstracts.80}

Introduction and Objectives Despite available evidence and recommendation, lung volume reduction (LVR) for severe emphysema remains under-utilised, due to a perception of excessive morbidity/mortality and associated costs. There is suggestion that outcomes may be more favourable in the warmer months, however benefits of this strategy remain uninvestigated. We aimed to review short-term outcomes of our LVR programme and assess whether seasonal variations can be observed.

Methods We retrospectively reviewed data from a prospectively collected database and electronic patient records. All consecutive procedures performed by thoracoscopy (LVRS), endobronchial valves (EBV) or endobronchial coils (EBC) between 2015-2021 were considered.

Results 105 primary procedures (43 LVRS, 45 EBV, 10 EBC) were undertaken in 98 patients (M:F 58:40, median age 66, 40-84). Second-stage contralateral procedures were 3 EBC and 4 LVRS (2 planned $<6$ months, 1 at further deterioration $>3$ yrs later, 1 salvage after poor response to EBV).

Median length of stay (LOS) for LVRS was 8 days (6-56), with $86 \%$ discharged within 14 days. Prolonged air leak $>7$ days was seen in 47\%. Median LOS was 3 days (2-55) for EBV, 2 days (1-6) for EBC. Pneumothorax occurred in 13 EBV (29\%) and 1 EBC, always within $72 \mathrm{hrs}$; median LOS in this group was 12 days (6-55).

LVRS was associated with highest rate of complications (48\% uncomplicated procedures vs $71 \%$ for EBV and $80 \%$ for EBC). Additional procedures were more likely required postEBV (12 vs 2 post-LVRS) for revision/reinsertion (8), removal (3) or air leak closure (1).

Critical care admission for the whole cohort was $6.6 \%$ (4 LVRS, 2 EBV). 90-day mortality was 4\% (3 after LVRS within 30-days, 1 post-EBV revision at 54-days).

Procedures were equally distributed across all seasons. Uncomplicated procedures were significantly more frequent in the summer (62\%) vs winter (33\%) for LVRS, but not for EBV/EBC. LOS was not significantly dissimilar in all seasons for all modalities (table 1).

Conclusions Short-term clinical outcomes suggest perceptions of excessive morbidity are invalid. A near-50\% reduced complication rate of LVRS during summer vs winter is suggestive of possible seasonal variation, which may have implications for patient selection and MDT decision-making, and should encourage further investigation on the topic.

\section{S75 REDO BRONCHOSCOPY AFTER ENDOBRONCHIAL LUNG VOLUME REDUCTION - INDICATIONS AND IMPLICATIONS}

M Lee, R Baranowski, D Waller. Barts Thorax Centre, London, UK

\subsection{6/thorax-2021-BTSabstracts.81}

Background Endobronchial lung volume reduction (EBLVR) is an effective treatment in patients with severe emphysema. It is perceived as a low-risk, low-morbidity procedure but there is the potential for longer term complications requiring re-intervention. We have analysed our experience with revisional (redo) bronchoscopy to identify learning points for practice.

Method In a prospective cohort study of 58 patients, treated by an already experienced team, we have collected follow-up clinical data including the need, indication and outcome of redo bronchoscopy. We compared the characteristics of those requiring redo bronchoscopy with the remainder who did not.

Results 18 of 58 (31\%) patients required revisional bronchoscopy at a median interval of 6 (1-13) months after the initial procedure. The indications were: lack of initial deflation 4 (22\%); subsequent loss of initial deflation 12 (66\%); haemoptysis $1(6 \%)$ and secondary infection 1 (6\%). The findings at redo bronchoscopy included: valve blockage 9 (52\%) (5 due to mucus, 4 due to granulation) valve expectoration $5(28 \%)$, valve leakage $2(10 \%)$, valve colonisation $1(5 \%)$ and $1(5 \%)$ new development of collateral ventilation. Radiological valve anomalies were reported prior to redo bronchoscopy CT scans in only 9 of $18(50 \%)$ cases and included: valve migration in 4 , loss of volume reduction in 3 and valve blockage in 2 .

Whilst pre-operative airways obstruction was higher in the redo group the only other potential risk factor for revisional bronchoscopy was lower lobe position.

Conclusion The need for revisional bronchoscopy after initial EBLVR is unpredictable but frequently required and indicates the need for close follow up and a low threshold for re-intervention on clinical grounds alone if the initial outcome is suboptimal.

Abstract S74 Table 1 Summary table of median length of stay (LOS) and rate of uncomplicated procedures, stratified by modality and season

\begin{tabular}{|c|c|c|c|c|c|c|c|c|}
\hline & $\begin{array}{l}\text { Total Number of } \\
\text { Procedures }\end{array}$ & $\begin{array}{l}\text { Median LOS } \\
\text { EBV (days) }\end{array}$ & $\begin{array}{l}\text { Median LOS } \\
\text { LVRS (days) }\end{array}$ & $\begin{array}{l}\text { Median LOS } \\
\text { EBC (days) }\end{array}$ & $\begin{array}{l}\text { Uncomplicated } \\
\text { All modality (\%) }\end{array}$ & $\begin{array}{l}\text { Uncomplicated } \\
\text { EBV (\%) }\end{array}$ & $\begin{array}{l}\text { Uncomplicated } \\
\text { LVRS (\%) }\end{array}$ & $\begin{array}{l}\text { Uncomplicated } \\
\text { EBC (\%) }\end{array}$ \\
\hline Spring & 22 & 3 & 11.5 & $\mathrm{n} / \mathrm{a}$ & $54.5 \%$ & $66.7 \%$ & $40 \%$ & n/a \\
\hline Summer & 29 & 3 & 5 & 2 & $69 \%$ & $66.7 \%$ & $61.5 \%$ & $100 \%$ \\
\hline Autumn & 23 & 3 & 8 & 2 & $60.9 \%$ & $80 \%$ & $50 \%$ & $75 \%$ \\
\hline Winter & 24 & 3 & 6 & 3.5 & $62.5 \%$ & $75 \%$ & $33.3 \%$ & $50 \%$ \\
\hline
\end{tabular}




\section{Abstract S75 Table 1}

\begin{tabular}{|c|c|c|c|}
\hline Median (Range) & No Redo & Redo & $\mathrm{p}$-value \\
\hline Number & 40(22M:18F) & 18(11M:7F) & \\
\hline Age (Year) & $68(43-82)$ & $69(57-80)$ & 0.2605 \\
\hline $\mathrm{BMI}\left(\mathrm{Kg} / \mathrm{m}^{2}\right)$ & $22(13-37)$ & $25.4(16.1-34.2)$ & 0.1652 \\
\hline LUL:LLL & 23:10 & $5: 5$ & NS \\
\hline RUL:RLL & $5: 2$ & $4: 4$ & NS \\
\hline Upper:Lower & 28:12 & $9: 9$ & 0.237 \\
\hline FEV1 (\%predicted) & $28.8(13.8-58)$ & $35.3(17-62)$ & 0.0351 \\
\hline DLCO (\%predicted) & $37.8(10.7-84)$ & $38(19-61)$ & 0.4346 \\
\hline RV (\%predicted) & $209(43.2-350.6)$ & $211(130-289)$ & 0.1750 \\
\hline \multicolumn{4}{|l|}{ Fissure Integrity } \\
\hline Target:Non-Target Lobe Volume Ratio & $1.12(0.6-2.22)$ & $0.96(0.48-1.56)$ & 0.1429 \\
\hline Target:Non-Target Lobe Perfusion Ratio & $0.4(0-1.5)$ & $0.32(0.19-0.91)$ & 0.2214 \\
\hline $\begin{array}{c}\text { Target:Non-Target Lobe Emphysema } \\
\text { Severity (Voxel Density <910 HU) }\end{array}$ & $1.25(0.67-6)$ & $1.23(0.83-2.86)$ & 0.3494 \\
\hline $\begin{array}{c}\text { Target:Non-Target Lobe Emphysema } \\
\text { Severity (Voxel Density <950 HU) }\end{array}$ & $1.61(0.55-26.5)$ & $1.69(0.75-4.8)$ & 0.2492 \\
\hline Pathogenic Bacteria Post-Initial EBV & 3 & 2 & NS \\
\hline Pneumothorax Post-Initial EBV & 17 & 2 & NS \\
\hline
\end{tabular}

\section{S76 CHEST TRAUMA: AN EXPERIENCE OF A RESPIRATORY SUPPORT UNIT WITH LEVEL 2 CARE IN THE NORTH EAST OF ENGLAND}

K Jackson, T Basterfield, J Bates-Powell, A Aujayeb. Northumbria Healthcare NHS Foundation Trust, Newcastle upon Tyne, UK

10.1136/thorax-2021-BTSabstracts.82

Introduction Falls cause $75 \%$ of trauma in patients above 65 years of age and thoracic trauma is the second commonest injury; rib fractures are the commonest thoracic injury. There is wide variation in care. Older trauma patients are less likely to have trauma assessments. Rib fractures carry up to $12 \%$ mortality with up to $31 \%$ developing pneumonia. ${ }^{1}$ The number of fractures correlates with morbidity. Northumbria Healthcare has a team of respiratory consultants, physiotherapists, specialist nurses and anaesthetists for rib fracture management on a respiratory support unit.

Methods With Caldicott approval, basic demographics and clinical outcomes of patients admitted with thoracic trauma between Aug 20-Apr 21 were analysed. Descriptive statistical methodology was applied.

Results 119 patients were identified. Mean age was 71.1 years (range 23-97). 53 were male, 66 female. Mechanism of injury were falls from standing (65), falls down stairs/bed or in the bath (18), ladders (4), cycling (12), assault (3), road accidents (8) and 9 others (for example off horses). LOS was 7.3 days (range 1-54). 85 patients had more than 1 co-morbidity. 26 had a full trauma assessment and 75 had pan CTs. Mean number of rib fractures was 3.6. $31(26 \%)$ had a pneumothorax and/or haemothorax. 18 chest drains were inserted (all small bore) and 1 needle aspiration done. No cardiothoracic input was required. Isolated chest trauma was present only in 45 patients. All had pain team review, 22 erector spinae catheters were inserted with 2 paravertebral blocks. 82 patients did not require oxygen, 1 required CPAP and 1 HFNC. 7 needed intensive care transfer. 20 (17\%) developed pneumonias.16 (14\%) deaths occurred within 30 days (1 heart failure and cancer progression, 2 Covid and 14 pneumonias)all were in those with falls from standing. There was no correlation between number of fractured ribs, length of stay and mortality.

Conclusions High level care for thoracic trauma can be performed by the respiratory team with analgesia managed by the pain team. $42 \%$ of pneumothoraces/haemothoraces were observed. Falls from standing are associated with significant mortality and morbidity. The service is now complemented by a frailty assessment service.

\section{REFERENCE}

1. https://academic.oup.com/ageing/article/49/2/161/5673134

\section{S77 THE EFFECT OF SURGERY ON LUNG FUNCTION IN PATIENTS WITH IDIOPATHIC SCOLIOSIS}

${ }^{1}$ SA Trotter, ${ }^{1}$ IE Williams, ${ }^{1}$ EK Finnerty, ${ }^{2} \mathrm{M}$ Rutter, ${ }^{3} \mathrm{~S}$ Charlton, ${ }^{4}$ RIR Russell. ${ }^{1}$ School of Clinical Medicine, University of Cambridge, Cambridge, UK; ${ }^{2}$ Department of Lung Function, Cambridge University Hospitals NHS Trust, Cambridge, UK; ${ }^{3}$ Department of Physiotherapy, Cambridge University Hospitals NHS Trust, Cambridge, UK; ${ }^{4}$ Department of Paediatric Respiratory Medicine, Cambridge University Hospitals NHS Trust, Cambridge, UK

\subsection{6/thorax-2021-BTSabstracts.83}

Introduction Idiopathic scoliosis, the most common form of scoliosis, results in an abnormal lateral curvature of the spine. It typically affects children aged 10-16 and can result in pain and reduced respiratory function largely due to a restrictive lung defect. Treatment can involve bracing and surgical procedures and it is currently unclear how these treatments affect lung development.

Methods We performed lung function studies on 26 children with idiopathic scoliosis before and at 1-3 years after spinal surgery. Mean height for age was used to calculate lung function scores instead of measured height due to the effects of 